\title{
Local site effects in Kumamoto City revealed by the 2016 Kumamoto earthquake
}

\author{
Seiji Tsuno ${ }^{1 *} \mathbb{0}$, Masahiro Korenaga ${ }^{1}$, Kyosuke Okamoto ${ }^{1}$, Hiroaki Yamanaka ${ }^{2}$, Kosuke Chimoto ${ }^{2}$ \\ and Takeshi Matsushima ${ }^{3}$
}

\begin{abstract}
:
To evaluate local site effects in Kumamoto City, we installed six temporary seismic stations along a 6-km north-south survey line in the city immediately after the 2016 Kumamoto earthquake foreshock (Mj 6.4), which occurred on April 14, 2016. Seismic data from the 2016 Kumamoto earthquake (Mj 7.3), which occurred on April 16, 2016, were successfully recorded at two sites and indicated large amplitudes in the frequency range of $0.5-3 \mathrm{~Hz}$. Site amplifications estimated from weak ground motion data, with a station at Mt. Kinbo used as a reference, are relatively variable along this survey line; however, site amplification factors in the frequency range of $0.5-3 \mathrm{~Hz}$ are not large enough to explain the amplitudes produced by the main shock. Nevertheless, site amplifications estimated from strong ground motion data recorded at the two sites during the main shock are large in the frequency range of $1-3 \mathrm{~Hz}$. These findings reveal that the strong ground motions in the frequency range of $1-3 \mathrm{~Hz}$ were enhanced by nonlinear behavior of the subsurface soil in Kumamoto City. Moreover, it is observed that the frequency contents of the main shock data in the frequency range of $0.7-3 \mathrm{~Hz}$ differ significantly between the two sites, despite the proximity of these sites (600-m interval). Therefore, we also performed single-station microtremor measurements with an interval distance of approximately $100 \mathrm{~m}$ between these two sites. We confirmed that the peak frequencies of the horizontal-to-vertical spectral ratios of microtremors have trends that are similar to those of the site amplification factors between the two sites. However, these results could not explain the differences in strong ground motions observed at the two sites during the 2016 Kumamoto earthquake.
\end{abstract}

Keywords: Strong ground motion, Local site effect, Nonlinearity, Kumamoto City, 2016 Kumamoto earthquake

\section{Introduction}

Strong ground motions were observed in Kumamoto Prefecture, Japan, during the 2016 Kumamoto earthquake sequence, which occurred on April 14, 2016, at 21:26 JST (Mj 6.4) and April 16, 2016, at 1:25 JST (Mj 7.3). In Mashiki, where the maximum intensity value on the Japanese intensity scale (i.e., 7) was recorded, buildings were heavily damaged by the earthquake; therefore, a great deal of preliminary research has been carried out to investigate the strong ground motions in this area (e.g., Kawase et al. 2016; Yamanaka et al. 2016). However, in Kumamoto City, which is located approximately $15 \mathrm{~km}$

\footnotetext{
*Correspondence: stsuno@rtri.or.jp

${ }^{1}$ Railway Technical Research Institute, 2-8-38 Hikari-cho, Kokubunji-shi, Tokyo 185-8540, Japan

Full list of author information is available at the end of the article
}

from the Futagawa-Hinagu fault zone (e.g., Shimizu et al. 2016), a Japanese seismic intensity of $>6$ was recorded, with slight earthquake damage to buildings. Moreover, in Kumamoto City, large site amplifications are expected because of the soft soil sediments comprising the Kumamoto Plain.

The Kumamoto Plain extends across the northeastern part of Kumamoto Prefecture, Japan, and consists of a diluvial plateau on the western slope of Mt. Aso (Hoshizumi et al. 2004) and an alluvial plain formed by the Shirakawa and Midorikawa rivers (Ishizaka et al. 1995). In particular, the geology of the central to northern parts of Kumamoto City comprises alluvium deposited by the Shirakawa River, andesite widely distributed in and around Mt. Kinbo, and pyroclastic flow deposits from Mt. Aso (Hoshizumi et al. 2004). Regarding soil conditions, the Japan Seismic Hazard Information Station 
(J-SHIS) (Headquarters for Earthquake Research Promotion, Cabinet Office, Government of Japan, 2005) indicates $\mathrm{V}_{\mathrm{S}}^{30}$ (average shear wave velocity down to $30 \mathrm{~m}$ depth) values ranging from 155 to $405 \mathrm{~m} / \mathrm{s}$ on the Kumamoto Plain, and a value of $510 \mathrm{~m} / \mathrm{s}$ on Mt. Kinbo, which suggests that earthquake ground motions are greatly and intricately amplified in Kumamoto City, because of the soft and complex soil sediments comprising the Kumamoto Plain.

In this study, we investigate the local site effects in an area extending from the central to the northern parts of Kumamoto City, based mainly on seismic data obtained from temporary seismic observations conducted immediately after the 2016 Kumamoto earthquake foreshock.

\section{Seismic observations}

We installed six temporary seismic stations (KR01KR06) along a 6-km north-south survey line in Kumamoto City immediately after the 2016 Kumamoto earthquake foreshock (Mj 6.4), which occurred on April 14,2016 . The locations of the temporary seismic stations are shown in Fig. 1. The observations were recorded using over-damped moving-coil-type accelerometers (JEP-6A3: $10 \mathrm{~V} / \mathrm{g}$, Mitutoyo Corp.) with flat response in the frequency range of $0.1-50 \mathrm{~Hz}$, and data loggers with 24-bit digitizer (LS-8800: GPS time synchronization, Hakusan-Kogyo Co. Ltd.) (Kudo et al. 2002). We conducted observations continuously from April 15, 2016, to May 19, 2016 (Table 1), and obtained seismic data from the main shock (Mj 7.3), which occurred on April 16, 2016, at stations KR02 and KR04.

In addition, a velocity seismometer (VSE-11F/12F, Tokyo Sokushin Co. Ltd.) was previously installed at station KU.KMP1, which is located on Mt. Kinbo where andesite is widely distributed (Hoshizumi et al. 2004), by the Institute of Seismology and Volcanology, Faculty of Science, Kyushu University. We adopted the seismic data recorded at KU.KMP1 as a reference.

We fully analyzed the seismic data from 48 earthquake events with magnitudes $(\mathrm{Mj})$ of $\geq 3.5$ on the Japan Meteorological Agency (JMA) (Fig. 1). Accelerations during an aftershock (Mj 5.8) that occurred in the Aso region on April 18, 2016, at 20:41 JST are shown in Fig. 2 and Table 1. The amplitude from KU.KMP1 shows

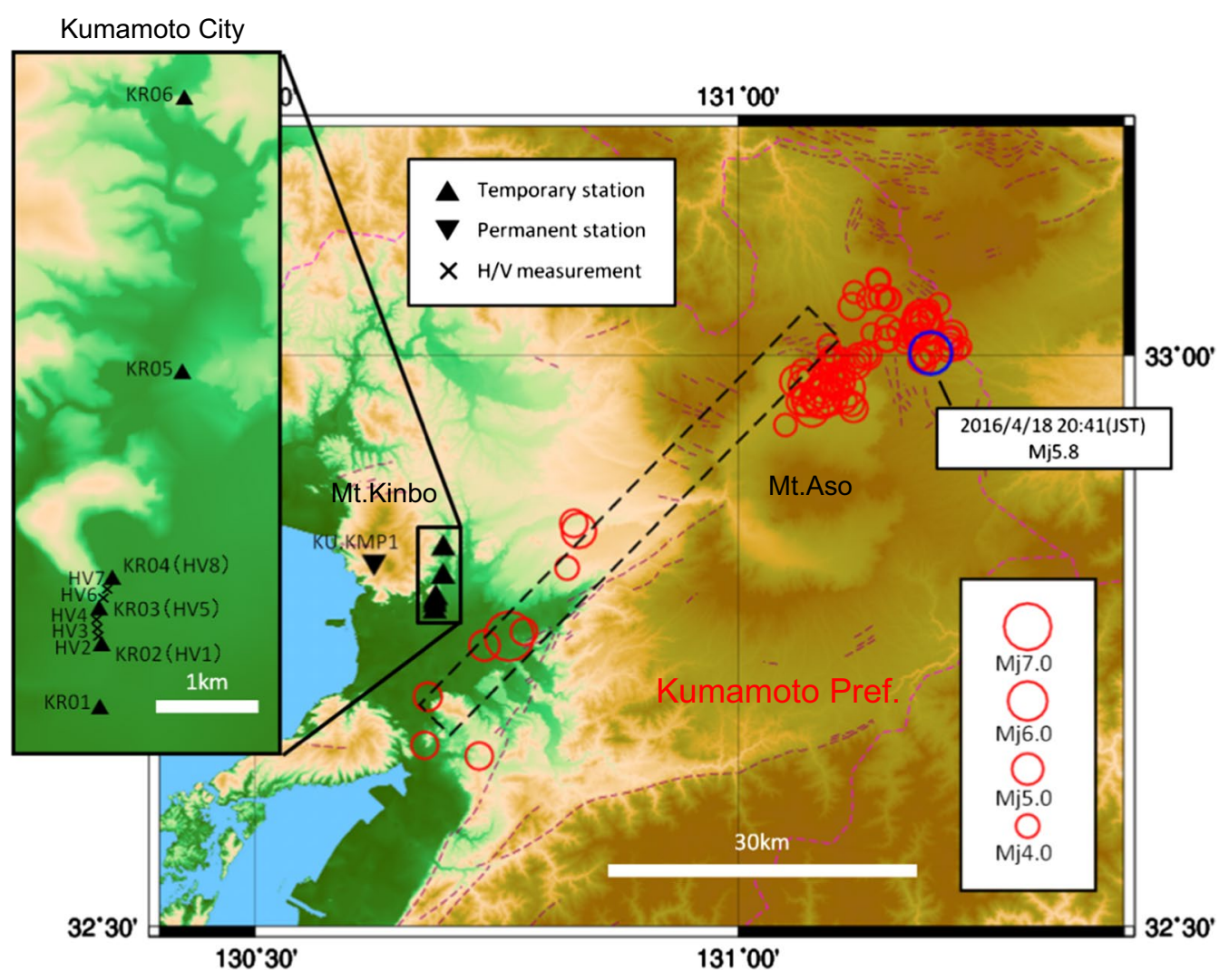

Fig. 1 Locations of temporary/permanent seismic stations and single-station microtremor measurements. Epicenters of earthquakes included in this study and the fault plane of the 2016 Kumamoto earthquake projected to the surface (Kobayashi et al. 2016) are indicated by red circles and a dashed rectangle, respectively 
Table 1 List of temporary seismic stations and one permanent seismic station with site information from surficial geological data and seismic data

\begin{tabular}{|c|c|c|c|c|c|c|c|c|c|c|}
\hline \multirow[t]{2}{*}{ Code } & \multirow[t]{2}{*}{ Lat. (N) } & \multirow[t]{2}{*}{ Long. (E) } & \multirow[t]{2}{*}{ Start (JST) } & \multirow[t]{2}{*}{ End (JST) } & \multirow{2}{*}{\multicolumn{2}{|c|}{ Geology }} & \multicolumn{4}{|l|}{$\mathrm{V}_{\mathrm{s} 30}(\mathrm{~m} / \mathrm{s})$} \\
\hline & & & & & & & \multicolumn{3}{|c|}{ Wald and Allen (2007) } & J-SHIS \\
\hline KR01 & 32.77614 & 130.68556 & 2016/04/16 02PM & 2016/05/19 00PM & \multicolumn{2}{|l|}{ Alluvium } & \multicolumn{2}{|l|}{$240-300$} & \multicolumn{2}{|c|}{155.4} \\
\hline KR02 & 32.78184 & 130.68575 & 2016/04/15 06PM & 2016/05/19 02PM & \multicolumn{2}{|l|}{ Alluvium } & \multicolumn{2}{|l|}{$490-620$} & \multicolumn{2}{|c|}{271.0} \\
\hline KR03 & 32.78511 & 130.68549 & 2016/04/16 02PM & 2016/04/21 11AM & \multicolumn{2}{|l|}{ Alluvium } & \multicolumn{2}{|l|}{$490-620$} & \multicolumn{2}{|c|}{278.7} \\
\hline KR04 & 32.78787 & 130.68690 & 2016/04/15 07PM & 2016/05/19 03PM & \multicolumn{2}{|l|}{ Alluvium } & \multicolumn{2}{|l|}{$490-629$} & \multicolumn{2}{|c|}{298.2} \\
\hline KR05 & 32.80654 & 130.69441 & 2016/04/16 01PM & 2016/05/19 01PM & \multicolumn{2}{|l|}{ Alluvium } & \multicolumn{2}{|l|}{$360-490$} & \multicolumn{2}{|c|}{235.8} \\
\hline KR06 & 32.83141 & 130.69463 & 2016/04/16 00PM & 2016/05/19 01PM & \multicolumn{2}{|c|}{ Pyroclastic flow deposits } & \multicolumn{2}{|l|}{$620-760$} & \multicolumn{2}{|c|}{405.6} \\
\hline KU.KMP1 & 32.81980 & 130.62270 & $\begin{array}{l}\text { Permanent } \\
\text { station }\end{array}$ & & $\begin{array}{r}\text { Early pleistocer } \\
\text { (Ko-kinbo vo }\end{array}$ & $\begin{array}{l}\text { e products } \\
\text { anic rocks) }\end{array}$ & 760 & & & 10.4 \\
\hline Epicentra & distance ( & & $\begin{array}{l}\text { Maximum ampl } \\
\text { 20:41 (JST) Mj5. }\end{array}$ & ude 2016/04/18 & Site amplificatio & factors usin & weak motion & data & & \\
\hline $\begin{array}{l}\text { 2016/04/ } \\
\text { (JST) Mj7 }\end{array}$ & & $\begin{array}{l}16 / 04 / 18 \\
41 \text { (JST) }\end{array}$ & $\begin{array}{l}\text { Horizontal } \\
\text { acceleration }\end{array}$ & $\begin{array}{l}\text { Horizontal } \\
\text { velocity }\end{array}$ & $\begin{array}{l}\text { Fundamental } \\
\text { frequency }(\mathrm{Hz})\end{array}$ & $\begin{array}{l}\text { Peak } \\
\text { amplitude }\end{array}$ & $\begin{array}{l}\text { Amplific } \\
\text { of freque }\end{array}$ & $\begin{array}{l}\text { Eation ove } \\
\text { encies (s) }\end{array}$ & r a rang & \\
\hline & & & & & & & $0.1-0.2$ & $0.2-0.5$ & $0.5-1$ & $1-2$ \\
\hline 7.64 & 54 & & 14.69 & 1.24 & 1.17 & 2.96 & 1.40 & 1.78 & 1.84 & 1.92 \\
\hline 7.85 & 53 & & 25.19 & 1.87 & 1.17 & 3.86 & 2.60 & 2.95 & 2.57 & 2.47 \\
\hline 8.01 & 53 & & 26.92 & 1.54 & 2.73 & 5.02 & 2.35 & 3.50 & 1.79 & 1.36 \\
\hline 8.03 & 53 & & 20.70 & 1.52 & 1.17 & 2.92 & 2.43 & 3.12 & 2.48 & 2.01 \\
\hline 8.63 & 52 & & 14.86 & 1.33 & 1.75 & 2.62 & 1.26 & 2.11 & 2.50 & 1.80 \\
\hline 10.66 & 50 & & 10.32 & 1.13 & 1.17 & 2.55 & 0.87 & 1.50 & 1.66 & 1.79 \\
\hline 15.00 & 57 & & 8.55 & 0.85 & - & - & - & - & - & - \\
\hline
\end{tabular}

Epicentral distances and the maximum amplitudes at the seismic stations for the 2016 Kumamoto earthquake and an aftershock (Mj 5.8) of that earthquake are indicated

the smallest peak ground acceleration (PGA), because of the location of this station on solid rock. Along the north-south survey line, accelerations recorded at the sites located in the south are generally larger than those recorded in the north. Among the six sites, the waveform amplitudes observed at KR02, KR03, and KR04 are large, and the records from these three stations include more high-frequency components. Despite the short length of the survey line (approximately $6 \mathrm{~km}$ ), the accelerations recorded at the six stations vary in amplitude and the timing of peak acceleration.

Accelerations during the main shock $(\mathrm{Mj} 7.3)$ recorded at KR02, KR04, and KU.KMP1 are shown in Fig. 3. The peak amplitudes at KR02 and KR04, which are located on sediments, exceed $450 \mathrm{~cm} / \mathrm{s}^{2}$. Vertical accelerations greater than $475 \mathrm{~cm} / \mathrm{s}^{2}$ at KR02 and KR04 were saturated because of the high sensitivity of the accelerometers $(10 \mathrm{~V} / \mathrm{g})$. At KU.KMP1, the records following the arrival of wave packets with the maximum amplitude were lost because of technical issues with the back-up battery. However, these records are still valuable for evaluating local site effects on strong ground motions during the main shock. We converted the original acceleration data to velocity and applied a high-pass filter with a cutoff frequency of $0.1 \mathrm{~Hz}$ to the velocity records from KR02, KR04, and KU.KMP1. The resultant velocity records are shown in Fig. 4, and the main phases are apparent.

Figure 5 shows the Fourier spectra, with a Parzen window of $0.4 \mathrm{~Hz}$, for the wave packets with the maximum amplitude recorded during the main shock at KR02, KR04, and KU.KMP1. Of the Fourier spectra for the main shock at the sediment-based sites, those for KR02 and KR04 have large amplitudes in the frequency range of $0.5-3 \mathrm{~Hz}$, particularly for the NS component of the ground motions at KR04. However, these Fourier spectra differ significantly in the frequency range of $0.7-3 \mathrm{~Hz}$, despite their close proximity of $600 \mathrm{~m}$ (Fig. 1). Naturally, earthquake ground motions observed at the sedimentbased sites, KR02 and KR04, are larger than those at the rock-based site, KU.KMP1, because of local site effects in Kumamoto City, regardless of the influence of seismic attenuation by geometric spreading. The $\mathrm{V}_{\mathrm{S}}^{30}$ estimated from the topographic slope (Wald and Allen 2007) and geological information (J-SHIS) has a larger value at the rock-based KU.KMP1 than at the sediment-based KR stations, as given in Table 1. 

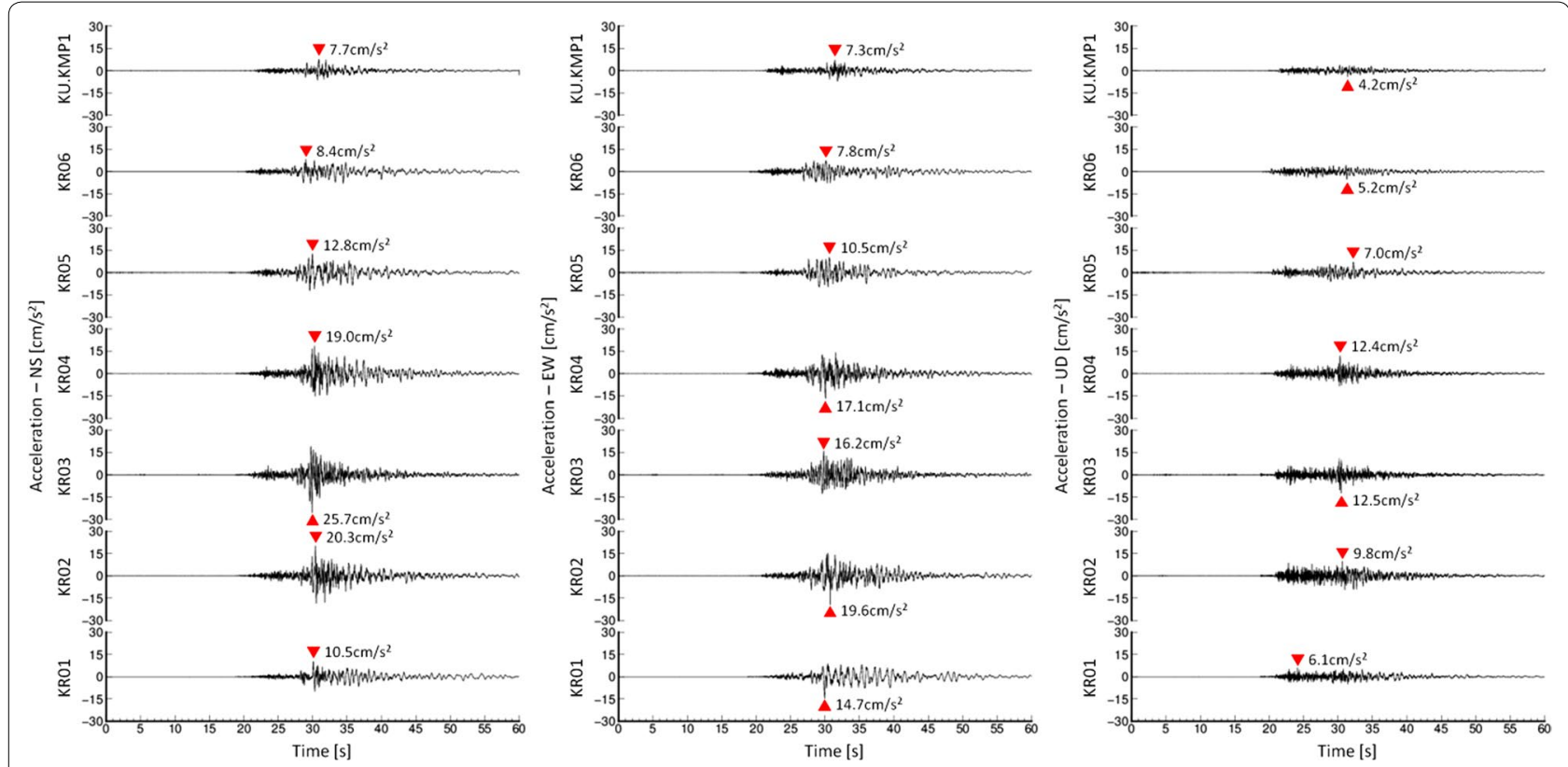

Fig. 2 Accelerations at seven seismic stations during an aftershock (Mj 5.8) of the 2016 Kumamoto earthquake, which occurred on April 18, 2016, at 20:41 JST. Triangles indicate the times when the peak acceleration was detected

\section{Site amplifications in Kumamoto City}

We estimated site amplification factors for the KR stations (KR01-KR06), using KU.KMP1 as a reference. We analyzed weak ground motions from the earthquake events that occurred in and around the Aso region (Fig. 1). To estimate the site amplification factors, firstly, we manually picked the $\mathrm{S}$-wave components of the accelerations and filtered velocities and calculated the Fourier spectra for a time window of $5.12 \mathrm{~s}$, with a Parzen window of $0.4 \mathrm{~Hz}$. Secondly, the Fourier spectra for the sediment-based KR stations were divided by those of the rock-based KU.KMP1, and these spectra were multiplied by the epicentral distances to account for seismic attenuation (Table 1). Finally, the derived spectral ratios were averaged as the arithmetic means of both their NS and EW components.

The site amplification factors for the six KR stations are shown in Fig. 6. Site amplifications at all the KR stations have factors larger than unity in the frequency range of $<10 \mathrm{~Hz}$. The site amplification factors for the sites located along the southern part of the survey line (KR01-KR04) are larger than those for the sites located along the northern part (KR05 and KR06), as is also the case for the observed accelerations. The site amplification factors for KR02 and KR04 are large at a frequency of $5 \mathrm{~Hz}$, and the site amplification factors for KR03 are large in the frequency range of 2.5-4 Hz. For all sites except KR03, the site amplification factors have a certain value at a frequency of around $1 \mathrm{~Hz}$; however, the amplification factor for KR03 is clearly smaller. These site amplification characteristics (Table 1) indicate soft and complex soil sediment cover along this survey line. Site amplification factors for some sites may be less than unity in the frequency range of $>10 \mathrm{~Hz}$ because the surface at the rockbased KU.KMP1 is also likely to be covered by thin soft soil sediments (e.g., $\mathrm{V}_{S}^{30}$ indicated by J-SHIS in Table 1).

\section{Nonlinearity during the main shock}

Of the sediment-based sites, seismic data from the 2016 Kumamoto earthquake main shock (Mj 7.3) were recorded at KR02 and KR04, as well as at the rock-based KU.KMP1 (Figs. 3, 4). Therefore, we estimated site amplification factors for the strong ground motions at KR02 and KR04 using the same procedure and reference site as those adopted in the analysis of the weak ground motions.

The site amplification factors for the 2016 Kumamoto earthquake at KR02 and KR04 are shown in Fig. 7. Figure 7 also lists the site amplification factors categorized into three acceleration ranges $\left(0-20 \mathrm{~cm} / \mathrm{s}^{2}, 20-50 \mathrm{~cm} / \mathrm{s}^{2}\right.$, and $50-150 \mathrm{~cm} / \mathrm{s}^{2}$ ) at KR02 and KR04 based on the seismic data from the aftershocks. Earthquake events that occurred within a $30-\mathrm{km}$ radius of Kumamoto City were included in these results.

In contrast to the categorized accelerations, the site amplifications for the 2016 Kumamoto earthquake at KR02 and KR04 are significantly larger within the frequency range of $1-3 \mathrm{~Hz}$. Moreover, the site amplification 


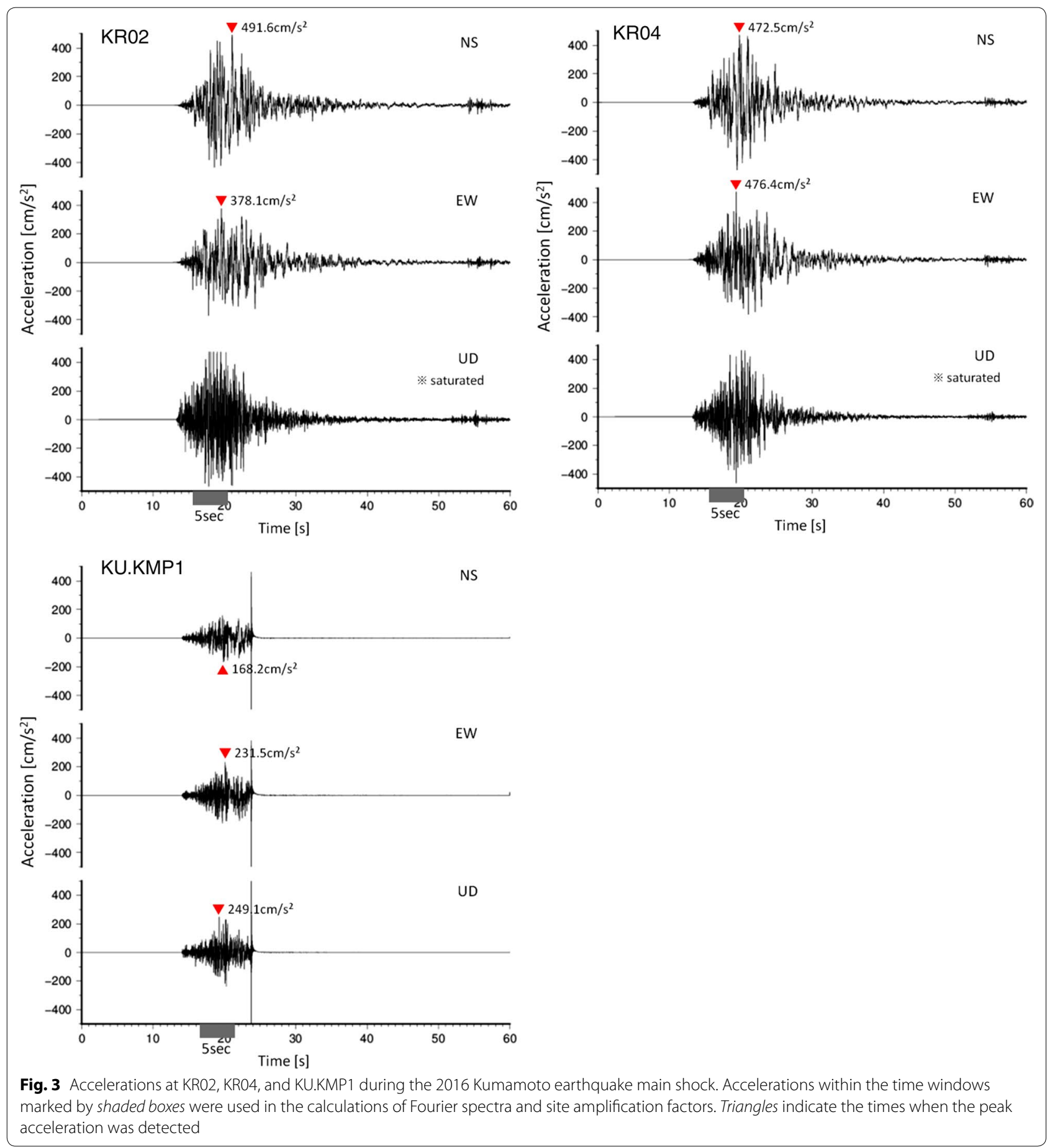

factors decrease notably in the high-frequency range of 10-20 Hz. These observations (e.g., Field et al. 1998) indicate that the seismic response of subsurface soils in Kumamoto City during the 2016 Kumamoto earthquake main shock was nonlinear. In contrast, the site amplifications for the categorized accelerations tend to be similar, which indicate that the subsurface soils behaved linearly during ground shaking at accelerations of less than $150 \mathrm{~cm} / \mathrm{s}^{2}$.

\section{Discussion}

As mentioned above, the strong ground motions in the frequency range of $1-3 \mathrm{~Hz}$ observed at sites KR02 and KR04 in Kumamoto City during the 2016 Kumamoto earthquake main shock ( $\mathrm{Mj} 7.3$ ) were influenced by nonlinear behavior of the subsurface soil, which shortens the peak frequency and weakens the amplitude at high frequencies. However, the Fourier spectra for KR02 and 


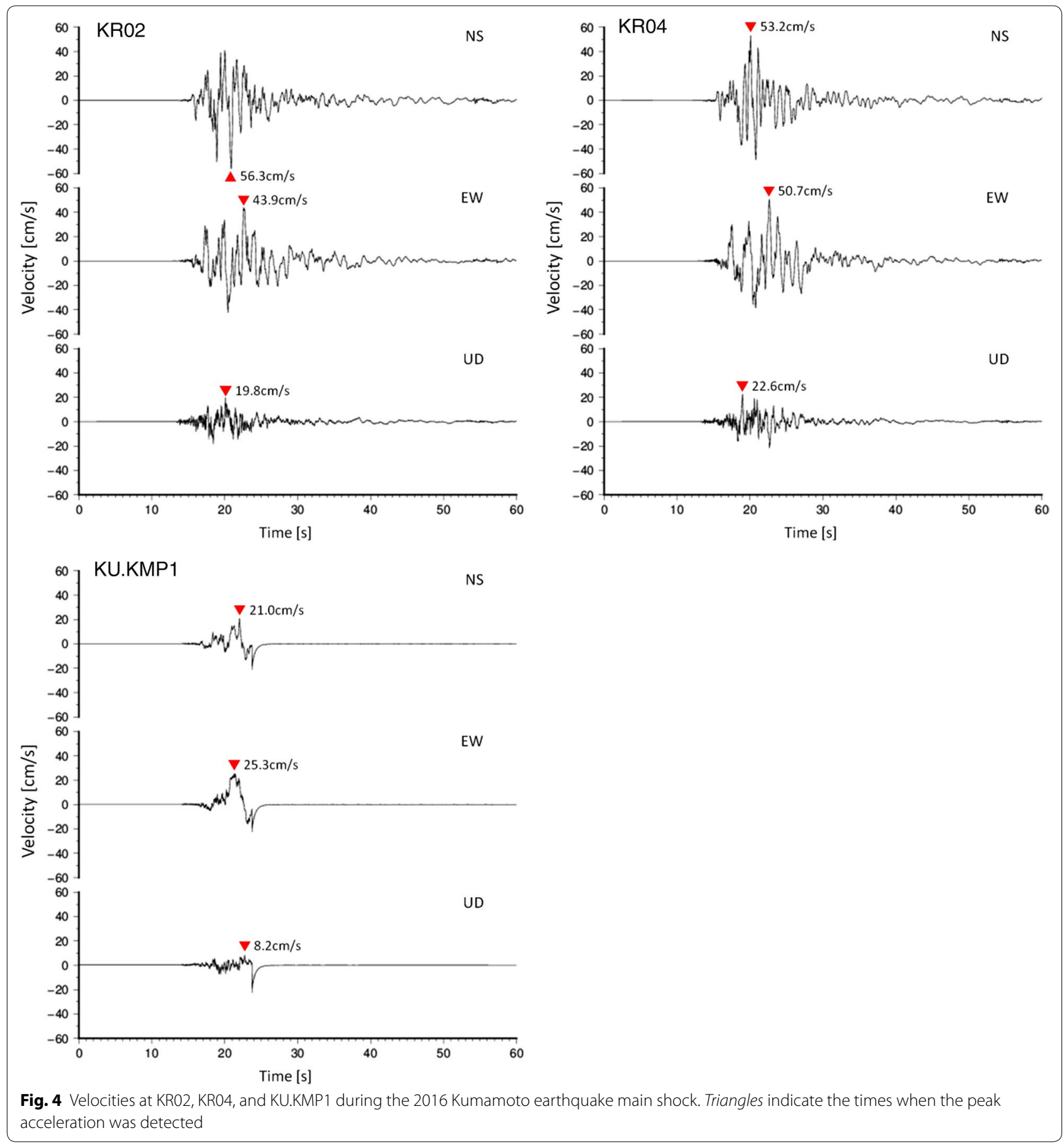

KR04 differ significantly within the frequency range of $0.7-3 \mathrm{~Hz}$ (Fig. 5), despite their close proximity of $600 \mathrm{~m}$ (Fig. 1). To understand the lateral heterogeneity in subsurface structure between KR02 and KR04, we performed single-station microtremor measurements with an interval distance of approximately $100 \mathrm{~m}$ along the survey line between KR02 and KR04 on May 22 and 23, 2016.
For these single-station microtremor measurements, we used the same instruments (accelerometer: JEP-6A3; data logger: LS-8800) as for the temporary seismic observations. We calculated the horizontal-to-vertical $(\mathrm{H} / \mathrm{V})$ spectral ratios of the microtremors using the geometric means of the NS and EW components and selected the 

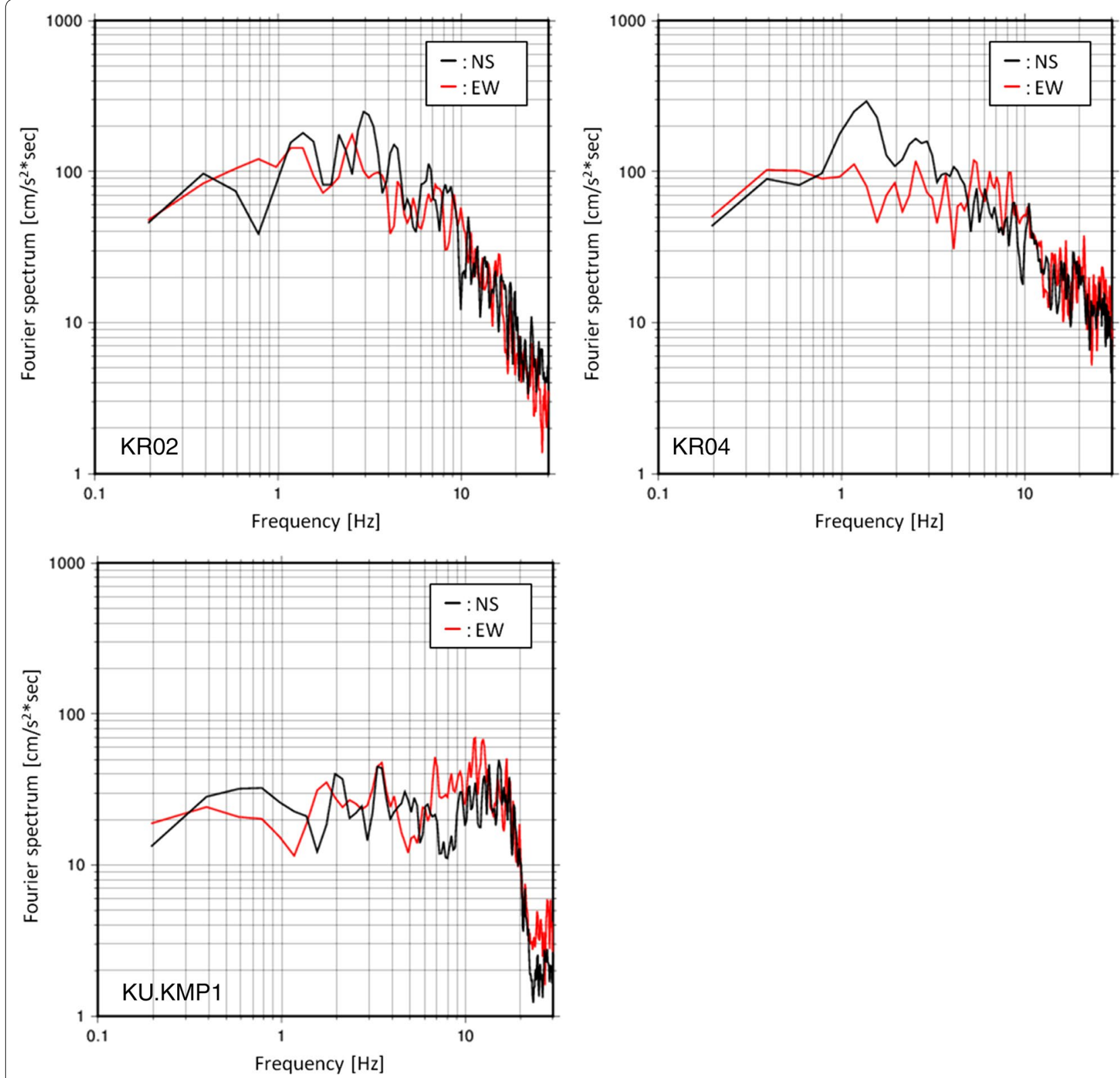

Fig. 5 Fourier spectra for KR02, KR04, and KU.KMP1 during the 2016 Kumamoto earthquake main shock

signal $15 \mathrm{~min}$ in length with a high signal-to-noise ratio by removing artificial noise from the original data.

The H/V spectral ratios of the microtremors obtained along the survey line between KR02 and KR04 are shown in Fig. 8. Although the amplitudes of these $\mathrm{H} / \mathrm{V}$ spectral ratios vary between sites $\mathrm{HV} 1-\mathrm{HV} 8$, the $\mathrm{H} / \mathrm{V}$ spectral ratios along this survey line are typically large within the frequency range of $1-2 \mathrm{~Hz}$, except for that of HV5 (KR03). The peak frequencies of the H/V spectral ratios indicate that a common subsurface layer may occur at a certain depth along this survey line. However, the peak frequency of the $\mathrm{H} / \mathrm{V}$ spectral ratio at HV5 (KR03), in which the $\mathrm{L}^{1}$ norm of the sum of the absolute values of the residuals in the frequency range of $0.2-10 \mathrm{~Hz}$ between the H/V spectral ratio at KR03 and the median for all sites is largest (Fig. 8), has a similar characteristic to the site amplification factor at KR03 with large values in the frequency range of $2.5-4 \mathrm{~Hz}$, as shown in Fig. 6.

An important issue for earthquake engineering in this area is to understand the differences between the Fourier spectra for sites KR02 and KR04 (Fig. 5), which are located in close proximity of $600 \mathrm{~m}$; however, we could 

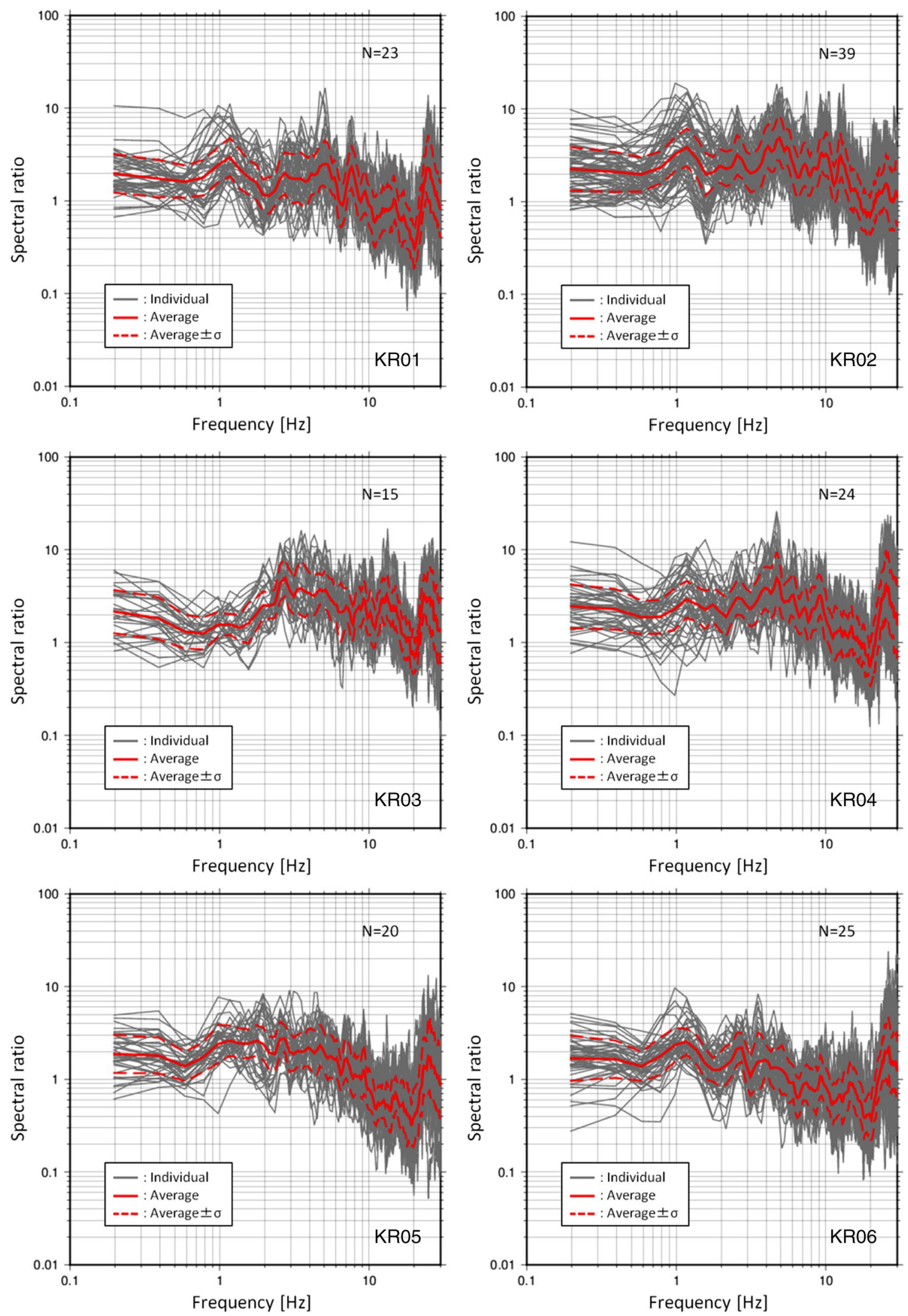

Fig. 6 Site amplification factors estimated from weak ground motion data at the six temporary seismic stations. $N$ indicates the number of earthquake events 

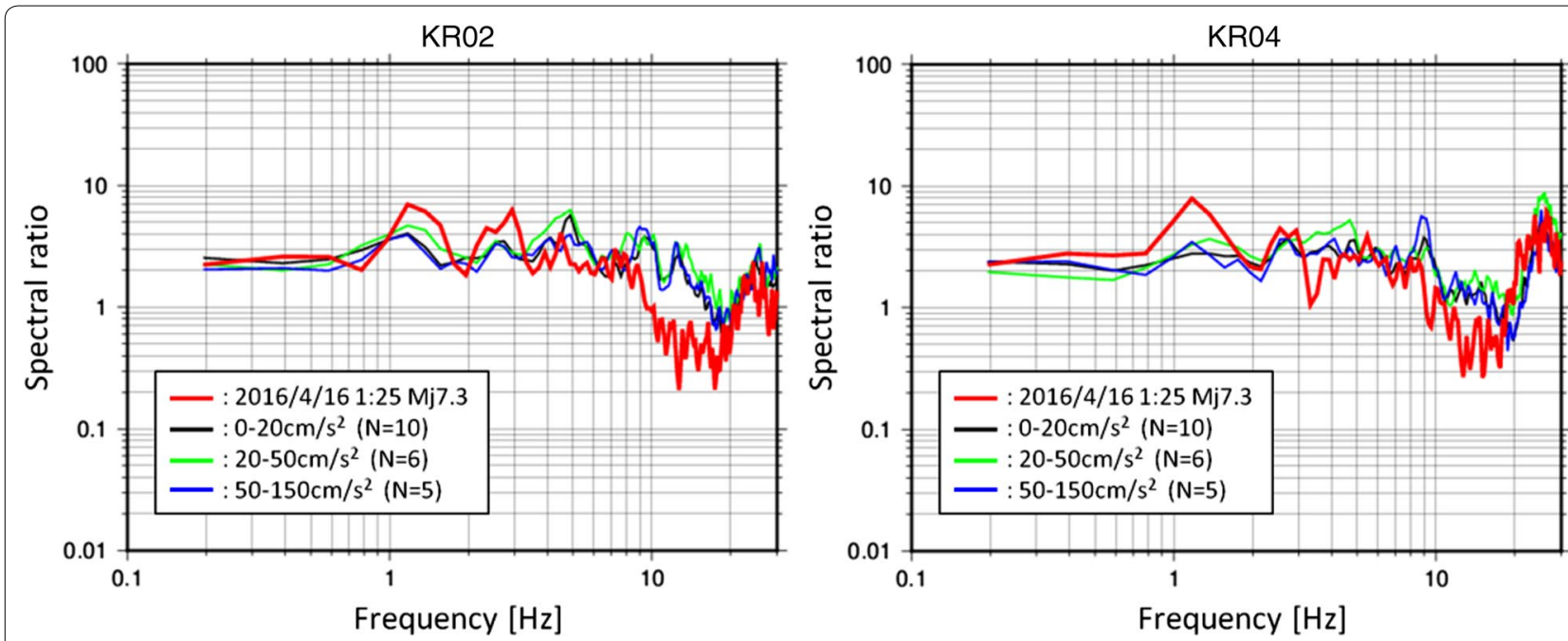

Fig. 7 Comparison of site amplification factors for weak ground motions with those for strong ground motions at KR02 and KR04. N indicates the number of earthquake events used in the calculations of site amplification factors

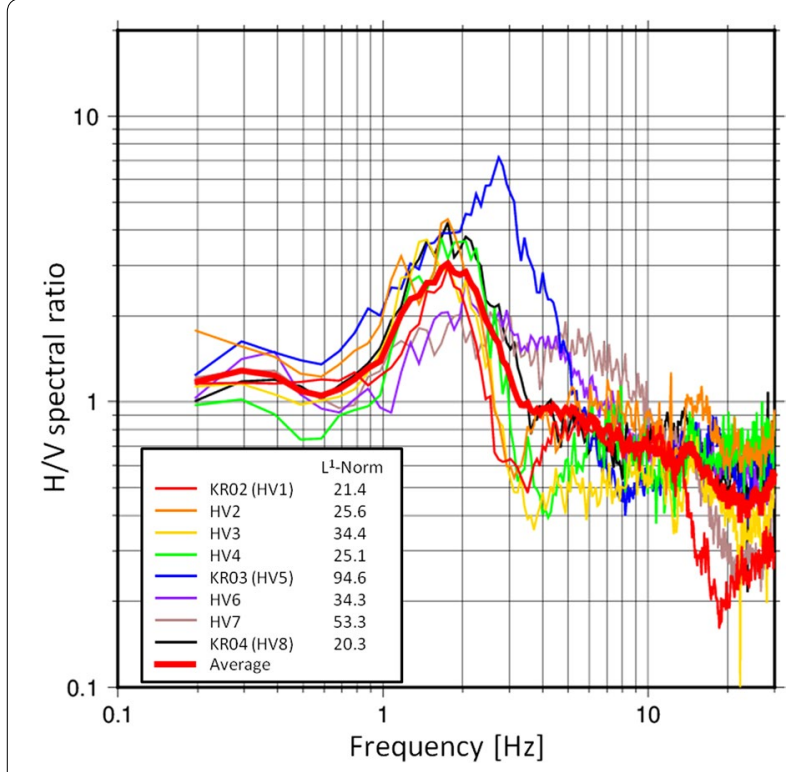

Fig. $8 \mathrm{H} / \mathrm{N}$ spectral ratios of microtremors with an interval distance of $100 \mathrm{~m}$ between $\mathrm{KRO} 2$ and $\mathrm{KRO} 4$. The $\mathrm{L} 1$ norm of the residual in the frequency range of $0.2-10 \mathrm{~Hz}$ between the $\mathrm{H} / \mathrm{N}$ spectral ratio at each station and the median for all sites are indicated

not determine the reason for these differences from the $\mathrm{H} / \mathrm{V}$ spectral ratio of microtremor results. The nonlinear behavior characteristics identified at KR02 and KR04, caused by local site conditions in the near surface, may be a major cause of these differences in strong ground motions. However, as pointed out by Kaklamanos et al. (2015), compounding factors such as basin waves, path effects, soil heterogeneity, and nonvertical incidence can greatly reduce the accuracy of $1 \mathrm{D}$ site response assumptions. The north-south survey line in this study is located close to Mt. Kinbo; therefore, basin waves refracted by the edge of the basin as well as topographic effects associated with Mt. Kinbo may influence the site responses and compound the nonlinear behaviors.

\section{Conclusions}

Seismic data from the 2016 Kumamoto earthquake (Mj 7.3) were successfully recorded at sites KR02 and KR04 located along a north-south survey line in Kumamoto City; these data show that the seismic waves recorded at these stations had large amplitudes in the frequency range of 1-3 Hz. Site amplifications for the weak ground motions were calculated with respect to a permanent station located at Mt. Kinbo as a reference, and the derived amplifications are relatively variable along the $6-\mathrm{km}$ survey line; however, site amplification factors in the frequency range of $0.5-3 \mathrm{~Hz}$ are not large enough to explain the amplitudes produced by the main shock. Moreover, site amplifications for the 2016 Kumamoto earthquake at KR02 and KR04 are large within the frequency range of $1-3 \mathrm{~Hz}$, despite the dominance of those for the weak ground motions at a frequency of $5 \mathrm{~Hz}$. It is inferred that the large site amplification factors in the frequency range of $1-3 \mathrm{~Hz}$ were responsible for the nonlinear behavior of subsurface soil in Kumamoto City during the 2016 Kumamoto earthquake.

To understand the differences in the Fourier spectra between the closely located (600-m interval) stations KR02 and KR04, we also performed single-station microtremor measurements with an interval distance of 
approximately $100 \mathrm{~m}$ between these stations. We confirmed that the peak frequencies of the H/V spectral ratios have similar characteristics to those of the site amplification factors along the survey line. However, the $\mathrm{H} / \mathrm{V}$ spectral ratio results could not explain the differences between the Fourier spectra at KR02 and KR04. In future research, to further investigate the differences in strong ground motions between these two sites during the 2016 Kumamoto earthquake, we will perform array microtremor observations and examine the nonlinear behavior characteristics by drillings at both sites.

\section{Authors' contributions}

ST and MK analyzed the seismic data. ST drafted the manuscript. All the authors participated in the observations of strong ground motions and revised the manuscript.

\section{Author details}

${ }^{1}$ Railway Technical Research Institute, 2-8-38 Hikari-cho, Kokubunji-shi, Tokyo 185-8540, Japan. ${ }^{2}$ Tokyo Institute of Technology, 4259 Nagatsuta, Midori-ku, Yokohama, Kanagawa 226-8503, Japan. ${ }^{3}$ Kyushu University, 2-5643-29 Shin'yama, Shimabara, Nagasaki 855-0843, Japan.

\section{Acknowledgements}

We thank the Institute of Seismology and Volcanology, Faculty of Science, Kyushu University, for providing us with seismic data from the 2016 Kumamoto earthquake. We thank Mr. K. Wada and Dr. K. Sakai of the Railway Technical Research Institute for help in conducting the temporary seismic observations. We also thank two anonymous reviewers and the editor for their comments and suggestions, which significantly contributed to improving the quality of this paper.

\section{Competing interests}

The authors declare that they have no competing financial interests.

Received: 1 August 2016 Accepted: 28 February 2017

Published online: 07 March 2017

\section{References}

Field EH, Zeng Y, Johnson PA, Beresnev IA (1998) Nonlinear sediment response during the 1994 Northridge earthquake: observations and finite source simulations. J Geophys Res 103:26869-26883

Headquarters for Earthquake Research Promotion, Cabinet Office, Government of Japan (2005) Japan Seismic Hazard Information Station. http:// www.j-shis.bosai.go.jp/
Hoshizumi H, Ozaki M, Miyazaki K, Matsuura H, Toshimitsu S, Uto K, Uchiumi S, Komazawa M, Hiroshima T, Sudo S (2004) Geological map of Japan 1:200,000, Kumamoto, Geological Survey of Japan, AIST

Ishizaka S, Iwasaki Y, Hase Y, Watanabe K, Iwauchi A, Taziri M (1995) Subsidence and sediments of the last interglacial epoch in the Kumamoto Plain, Japan. Quat Res 34:335-344 (in Japanese with English abstract)

Kaklamanos J, Baise LG, Thompson EM, Dorfmann L (2015) Comparison of $1 \mathrm{D}$ linear, equivalent-linear, and nonlinear site response models at six KiK-net validation sites. Soil Dyn Earthq Eng 69:207-219. doi:10.1016/j. soildyn.2014.10.016

Kawase H, Matsushima S, Nagashima F, Bao Y (2016) The cause of heavy damage concentration in downtown Mashiki-cho inferred from observed data and field survey, Japan Geoscience Union Meeting, MIS34-08

Kobayashi H, Koketsu K, Miyake H (2016) Rupture processes of the 2016 Kumamoto earthquakes derived from joint inversion of strong-motion, teleseismic, and geodetic data, Japan Geoscience Union Meeting, MIS34-P65

Kudo K, Kanno T, Okada H, Ozel O, Erdik M, Sasatani T, Higashi S, Takahashi M, Yoshida K (2002) Site-specific issues for strong ground motions during the Kocaeli, Turkey, Earthquake of 17 August 1999, as inferred from array observations of microtremors and aftershocks. Bull Seismol Soc Am 92:448-465. doi:10.1785/0120000812

Shimizu H, lio Y, Sakai S, Okada T, Takahashi H, Watanabe T, Goto K, Ohkura T, Asano Y, Matsushima T, Yamashita Y, Nakamoto M, Miyazaki M, Matsumoto S, Aizawa K, Shito A, Uchida K, Miyamachi R, Kamizono M, Teguri Y, Miyamachi H, Nakao S, Yakiwara H, Hirano S, Ohzono M, Shiina T, Masamitsu T, Ichiyanagi M, Yamaguchi T, Okada K, Kosuga M, Azuma R, Uchida N, Emoto K, Ohta Y, Kaida T, Kozono T, Suzuki S, Takagi R, Demachi T, Nakahara H, Nakayama T, Hirahara S, Matsuzawa T, Miura S, Yamamoto M, Iwasaki T, Hirata N, lidaka T, Kurashimo E, Kato A, Nakagawa S, Yamanaka Y, Ito T, Terakawa T, Maeda Y, Horikawa S, Matsuhiro K, Okuda T, Katao H, Kano Y, Miura T, Tsuda H, Muramoto T, Okubo M, Yamashina T, Ueno T (2016) Urgent joint seismic observation of the 2016 Kumamoto earthquake-seismic activities and their background, Japan Geoscience Union Meeting, MIS34-02

Wald DJ, Allen TI (2007) Topographic slope as a proxy for seismic site conditions and amplification. Bull Seismol Soc Am 97:1379-1395. doi:10.1785/0120060267

Yamanaka H, Chimoto K, Miyake H, Tsuno S, Yamada N (2016) Observation of earthquake ground motion due to aftershocks of the 2016 Kumamoto earthquake in damaged areas. Earth Planets Space 68:197. doi:10.1186/ s40623-016-0574-2

\section{Submit your manuscript to a SpringerOpen ${ }^{\circ}$ journal and benefit from:}

- Convenient online submission

- Rigorous peer review

- Immediate publication on acceptance

- Open access: articles freely available online

- High visibility within the field

- Retaining the copyright to your article

Submit your next manuscript at springeropen.com 